\title{
Excellent vs. Good Range of Motion after TKA, What Makes the Difference?
}

\author{
Attaallh Alrefaee ${ }^{1 *}$, Samih Tarabichi ${ }^{1}$, Mohammad Alfeqqy ${ }^{2}$ and Dragos Apostu ${ }^{3}$ \\ ${ }^{1}$ Burjeel Hospital Dubai, UAE \\ ${ }^{2}$ Hatta Hospital \\ ${ }^{3}$ Iuliu Hatieganu University of Medicine and Pharmacy, Cluj-Napoca, Romania
}

Submission: January 10, 2017; Published: January 24, 2017

*Corresponding author: Attaallh Alrefaee, Burjeel Hospital for Advanced Surgery Dubai, Cornich Street, UAE, Tel: 555536381;

Email: ata-allah@live.com

\section{Abstract}

Background: Achieving full range of motion (ROM) is one of the most important goals in total knee replacement (TKA). The aim of this study was to identify surgical-dependent factors that are correlated to a full ROM.

Methods: Between August 2013 and July 2014, on 227 total knee replacements (132 patients), who were assessed for range of motion at least one month postoperatively, x-ray measurements were performed. We have included patient demographics (sex, age, body mass index and preoperative range of motion), type of TKA, as well as radiographic measurements including patella length, patellar height, Insall-Salvati Ratio, joint line to patella distance, joint line to tibial tubercle distance, joint line to fibula distance, joint line to medial epicondyle distance and other ratios. The total knee replacements were divided into two groups, an excellent ROM group (more than 130 degrees) and a good ROM group (between 110 and 129 degrees). The parameters were statistically analyzed.

Results: We found a statistically significant result in joint line to fibula head distance $(\mathrm{p}=0.01)$ with an average of $18.8 \mathrm{~mm}$ in excellent ROM group compared to $17.5 \mathrm{~mm}$ in the good ROM group. Also patellar length / joint line to tibial tubercle ratio difference between the two groups proved statistically significant $(\mathrm{p}=0.032)$. Other results included the ranges of all measurements associated with an excellent and good ROM.

Conclusion: Better range of motion after TKA is associated with a good control of joint line to fibula head distance and patellar length / joint line to tibial tubercle ratio. Many parameters can withstand a wide range without affecting ROM outcome.

Keywords: Knee; TKA; Arthroplasty; Range of Motion; X-Ray Measurements

\section{Introduction}

Total knee arthroplasty (TKA) is an effective procedure to reduce pain, correct leg deformities and improve the functional disability in patients with knee arthritis [1]. Achieving full range of motion (ROM) is one of the most important goals in TKA. This requires both a successful surgery and a good patient cooperation throughout their recovery. We consider that patients achieving full range of motion require an ideal surgical intervention, whilst patients which achieve a lesser range of motion, may have a patient-dependent issue, a surgicaldependent issue, or both. The purpose of our study is to identify surgical-dependent factors that are strongly associated with a full ROM and also factors that can undergo important variations without affecting it. These factors can be used not only to predict the patient's range of motion outcome but mainly to modify surgical aims. Therefore we have compared in matter of x-ray measurements total knee replacements that have an excellent ROM to total knee replacements that have only good ROM.

Not many studies exist in the literature regarding this issue $[2,3]$. A limitation of most studies is that they focus on few factors while our study takes into account a number of 9 different $x$-ray measurements and ratios $[2,3]$. We consider that having so many factors improve the quality of the study by making possible a comparison between them and finding out which are the most important. Some current surgical aims during TKA such as joint line to fibula distance, joint line to inferior pole of patella distances and more, are set by anatomical references [4,5]. We consider that due to mechanical changes after TKA, these aims should be changed for a better range of motion outcome.

Although differences in some measurements between groups might be of only several millimeters, considering that 
modern implants provide a greater intraoperative flexibility due to $2 \mathrm{~mm}$ increments, orthopedic surgeons will be able in many cases to achieve aims set preoperatively, a fact that helps patients achieve a full ROM outcome [5]. Moreover, identifying factors that, contradictory to current perceptions, can withstand important variation without affecting ROM, can increase intraoperative flexibility.

\section{Materials and Methods}

The total knee arthroplasties (TKA) included in the study was either bilateral or unilateral and were performed in our hospital on Arabic people by the same surgeon and team, according to the same protocol and with the same type of implant: cemented posterior stabilized. All surgeries were performed using a subvastus approach. Quadriceps release and tourniquet were also used in all cases. We have searched retrospectively our institution's electronic database on a period between August 2013 and July 2014 for patients which had underwent total knee replacement at our hospital and had both lateral and anteroposterior views $\mathrm{x}$-rays post-surgery. We have included only those patients which had done physiotherapy sessions at our institution and had a passive flexion of more than 110 degrees in the Physiotherapy Department Report or full flexion mentioned in the Medical Report. The Physiotherapy Department measurements were done using a goniometer.
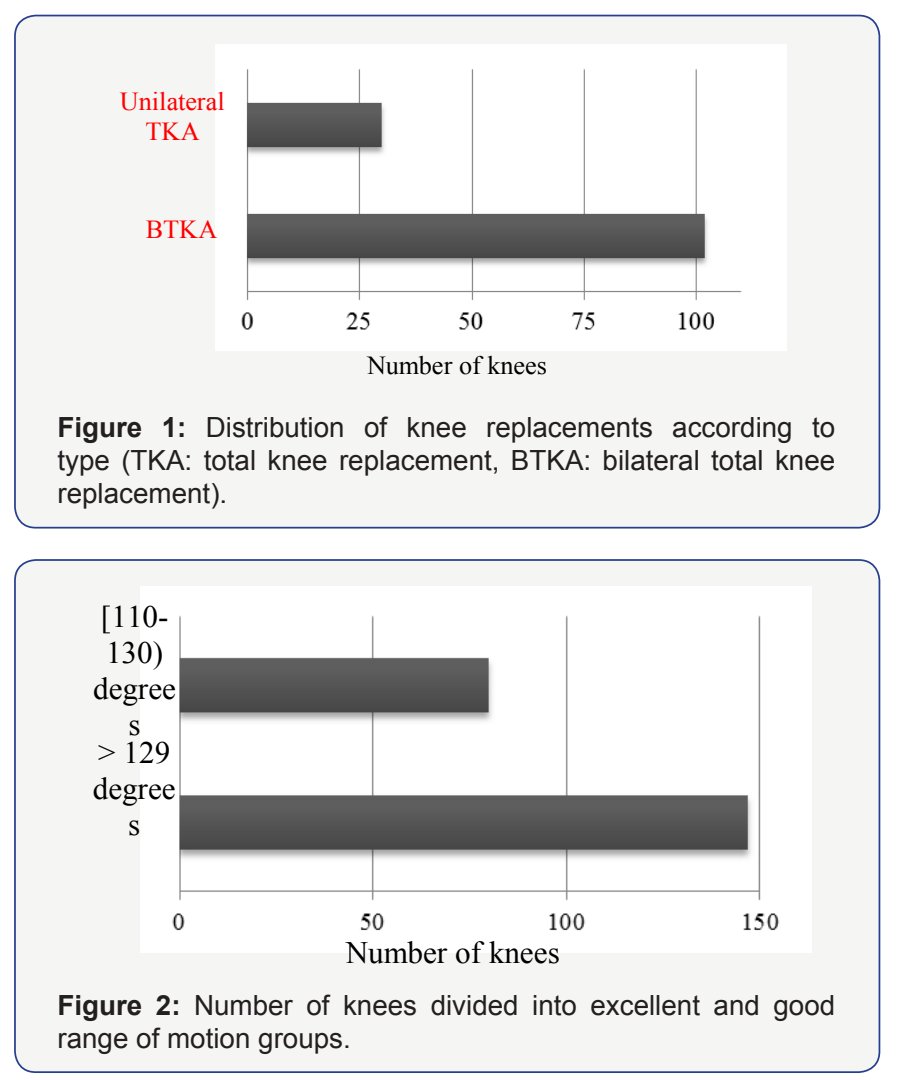

We have excluded patients with revision total knee replacement, constrained total knee replacement, time from surgery to range of motion assessment lower than 30 days, flexion contracture and lateral view $x$-rays that were not of $90 \pm 20$ degrees of flexion. The information taken into account for each case included: type of total knee replacement (unilateral or bilateral), range of motion, gender, age, height, weight, BMI, date of range of motion assessment, date of x-ray, date of surgery and time from surgery to range of motion assessment. Total knee replacements included were split into two groups: excellent range of motion group, for flexion 130 degrees or more and good range of motion group, for flexion between 110 and 129 degrees. Bilateral total knee replacement (BTKA) was performed in 102 patients and 30 unilateral total knee replacements (Figure 1). Corresponding to our criteria were 132 patients with 227 TKA, where 147 knees had excellent range of motion and 80 had good range of motion (Figure 2). From the BTKA patients, seven of them had one of the knees with a flexion lower than 110 degrees. Among these patients, 99 were female and 33 were male. The average age was 65 years and average BMI was 34 .

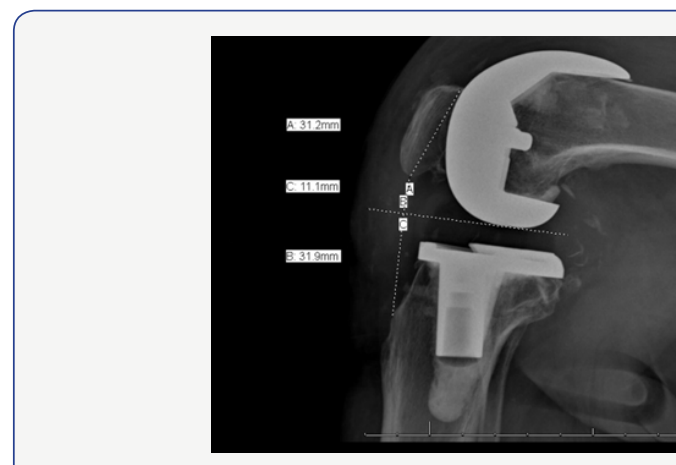

Figure 3: Measurements performed on lateral view x-ray.

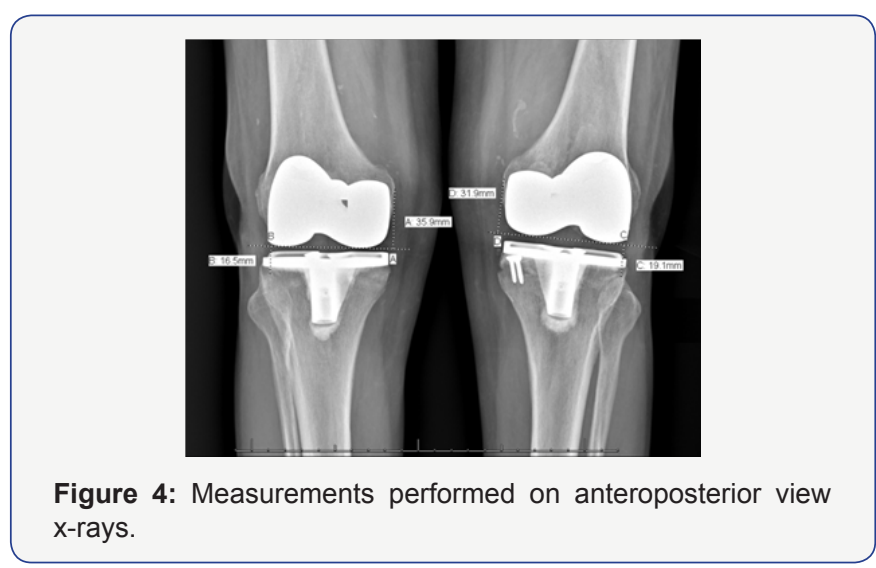

X-rays were done using a Juno Philips digital radiography system. We have measured patella length, patella height, inferior pole of patella to joint line distance, tibial tubercle to joint line distance on the lateral views (Figure 3) and medial epicondyle to joint line distance, fibula head on the anteroposterior views (Figure 4). Moreover we have calculated patellar height / joint line to tibial tubercle ratio, patellar length / joint line to tibial tubercle ratio and Insall-Salvati ratio. Measurements were done using Philips iSite Enterprise version 4.1.130 software. The total number of measured knees was 211 in which 134 knees had excellent flexion and 77 knees had a good flexion. There were 15 
cases where medial epicondyle to joint line distance and 3 cases where fibula head to joint line distance could not be measured on the anteroposterior x-rays. Measurements were performed by the same person and double-checked.

For each TKA in the database we have searched for implant details including implant make, implant model, femoral component type, femoral component size, tibial component size, and spacer size. Implant details were found for a total of 172 total knee replacements from which 117 TKA with flexion of 130 degrees or higher and 55 TKA with flexion between 110 and 129 degrees (Table 1). Most used implant type was Persona from Zimmer, in 145 total knee replacements, while other types including Zimmer NexGen, Maxx Freedom, Stryker were only used on 27 total knee replacements. Statistical analysis was performed using student test, correlation test and other descriptive statistics parameters such as mean, average, mean, maximum and minimum variables.

Table 1: Number of cases included in the study.

\begin{tabular}{|c|c|c|c|}
\hline & \multicolumn{2}{|c|}{ ROM } & Total \\
\hline & $\begin{array}{c}\text { [110-129] } \\
\text { degrees }\end{array}$ & $\begin{array}{c}\mathbf{> 1 2 9} \\
\text { degrees }\end{array}$ & \\
\hline Knees in database & 80 & 147 & 227 \\
\hline $\begin{array}{c}\text { Knees measured } \\
\text { Knees measured with implant } \\
\text { details }\end{array}$ & 55 & 117 & 172 \\
\hline
\end{tabular}

ROM: Range of Motion

Results

A total number of 211 knees following total knee replacement and having a flexion of 110 degrees or more have been measured for patella length, patella height, inferior pole of patella to joint line distance, tibial tubercle to joint line distance, medial epicondyle to joint line distance and fibula head to joint line distance. We have also calculated Insall-Salvati ratio, patellar length / joint line - tibial tubercle ratio, patellar height / joint line - tibial tubercle ratio. Two-tailed Student's t-test for two samples with unequal variance was performed for every measurement mentioned above comparing excellent range of motion group $(n=134)$ to good range of motion group $(n=77)$.

Statistically significant difference was in joint line - fibula head distance $(p=0.010)$. The average of this distance in the excellent range of motion group $(n=130)$ was $18.8 \mathrm{~mm}$, compared to the good range of motion group $(n=78)$ where it was $17.5 \mathrm{~mm}$, resulting in a difference of $1.3 \mathrm{~mm}$. The joint line - fibula head distance range associated with excellent ROM was [11.8-27.6] mm compared to ranges associated with only good ROM [5.3-28.5] mm. Other measurements on the same groups including patella length $(\mathrm{p}=0.165)$, inferior pole of patella to joint line distance $(p=0.419)$, tibial tubercle to joint line distance $(p=0.229)$, medial epicondyle to joint line distance $(p=0.136)$ showed no statistically significant difference between the two groups.

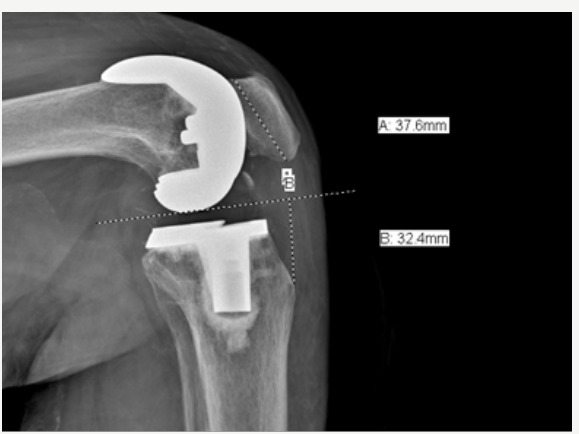

Figure 5: Patellar length / joint line - tibial tubercle ratio measurement.

On a number of 107 knees with excellent ROM and 77 knees with good ROM we had calculated the patellar length / joint line tibial tubercle ratio (Figure 5). Student t-test comparing the two groups showed a statistically significant difference $(p=0.032)$. Knees with good flexion have a greater interval in patellar length / joint line - tibial tubercle ratio values compared to knees with excellent flexion: [0.798-1.368] in good and [0.88-1.328] in excellent group (Figure 6). On the other hand, the average between the two groups was similar, 1.099 in excellent ROM and 1.065 in good ROM. There was also no correlation between patellar length / joint line - tibial tubercle ratio and ROM within the 184 knees studied ( $r=.092)$.

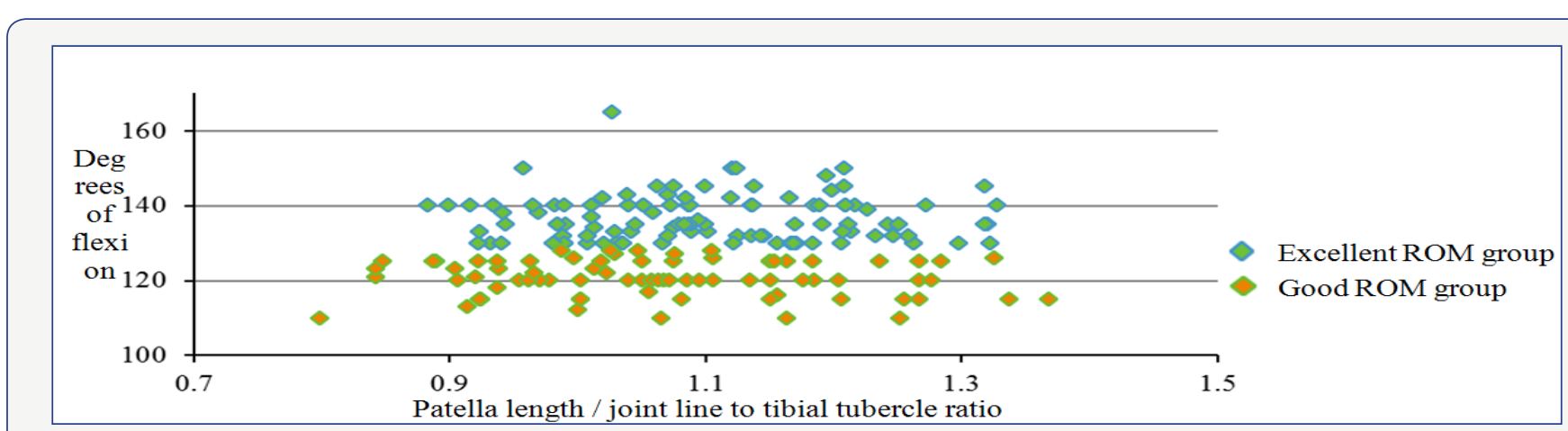

Figure 6: Excellent and good ROM groups in relation to patella length / joint line to tibial tubercle ratio (ROM: range of motion). 
Other significant results included that men have a better flexion after TKA compared to female, average in male $(n=48)$ was 133 degrees and in female $(n=161)$ was 127 , showing a difference of 6 degrees ( $p=0.00009)$. Also female in our study needed TKA at a younger age compared to male, the average in female was 63 years and in male was 68 years $(p=0.004$, $\mathrm{n}($ female $)=71, \mathrm{n}($ male $)=26)$. Regarding Zimmer Persona, which was the most used implant in our study, we found out that narrow femoral implants $(n=23)$ had a better flexion $(p=0.0013)$ compared to the standard ones $(n=131)$. From 23 narrow implants, 22 had excellent ROM, compared to standard ones which from a total of 131 only 76 had an excellent ROM.

Table 2: Measurements and ratios ranges associated with excellent range of motion.

\begin{tabular}{|c|c|c|}
\hline Measurement or ratio & Excellent ROM & Good ROM \\
\hline BMI & {$[23.9-52.7]$} & {$[25.3-52.8]$} \\
\hline Patellar length (mm) & {$[30.9-48.5]$} & {$[29.9-46.7]$} \\
\hline $\begin{array}{c}\text { Joint line to inferior pole of patella } \\
\text { distance (mm) }\end{array}$ & {$[2.1-29.9]$} & {$[4.7-58.9]$} \\
\hline $\begin{array}{c}\text { Patellar height / joint line to tibial } \\
\text { tubercle ratio (mm) }\end{array}$ & {$[28-47.4]$} & {$[24.9-46.7]$} \\
\hline $\begin{array}{c}\text { Patellar length / joint line to tibial } \\
\text { tubercle ratio }\end{array}$ & {$[1.04-1.91]$} & {$[1.1-2.77]$} \\
\hline $\begin{array}{c}\text { Joint line to head of fibula distance } \\
\text { (mm) }\end{array}$ & {$[11.8-27.6]$} & {$[5.3-28.5]$} \\
\hline $\begin{array}{c}\text { Medial epicondyle to joint line } \\
\text { distance (mm) }\end{array}$ & {$[23.5-42]$} & {$[26-41.8]$} \\
\hline $\begin{array}{c}\text { Patellar height (mm) } \\
\text { Insall-Salvati ratio }\end{array}$ & {$[40.9-68]$} & {$[32.1-92.1]$} \\
\hline
\end{tabular}

\section{ROM: Range of Motion; BMI: Body Mass Index}

Regarding how much can distances and ratios range and still be associated with an excellent ROM, we have found the following: joint line to inferior pole of patella distance [2.1-29.9] $\mathrm{mm}$, tibial tubercle to joint line distance [28-47.4] mm, medial epicondyle to joint line distance [24.5-42] mm, Insall-Salvati ratio [0.97-1.66] (Table 2). Age has shown no correlation with flexion outcome in 215 knees in our study ( $\mathrm{r}=.051)$. Moreover, BMI, with a range of 24 to 53 , has been shown to have a weak correlation with patient's flexion after TKA ( $\mathrm{r}=-\mathrm{279}$ ) on 154 knees studied. A moderate relationship has been found between BMI and age needed TKA in 99 patients ( $r=-.297)$ showing that the higher the BMI the earlier the surgery needed. No correlation has been demonstrated between ROM and femoral component size ( $\mathrm{r}=.035)$, tibial implant size $(\mathrm{r}=.062)$ and spacer size ( $\mathrm{r}=.148)$ in 130 knees.

No statistically significant difference has been found between bilateral TKA $(n=188)$ and unilateral TKA $(n=24)$ when it comes to outcome of flexion degrees $(p=0.243)$. No difference as well has been reported on ROM in right $(n=103)$ and left $(\mathrm{n}=109)$ knees $(\mathrm{p}=0.392)$. There has been no proven statistically significant difference and correlation in comparing ROM to patellar height ( $\mathrm{p}=0.261$ and $\mathrm{r}=-.052, \mathrm{n}=182$ ) and Insall-Salvati ratio ( $\mathrm{p}=0.149$ and $\mathrm{r}=-.109, \mathrm{n}=182)$. From the total of 182 knees used in the last two interpretations, 104 had excellent flexion and 78 had good flexion. A summary of the study's results along with details and interpretation can be found in (Table 3).

Table 3: Summary of results with details and interpretation.

\begin{tabular}{|c|c|c|c|c|c|c|c|}
\hline $\begin{array}{l}\text { Parameter or } \\
\text { correlation }\end{array}$ & Type of test & Results & Type of test & Results & Type of test & Results & Interpretation \\
\hline & & & \multicolumn{2}{|c|}{ ROM > 129o } & \multicolumn{2}{|c|}{ ROM between $110^{\circ}$ and $129 \circ$} & \\
\hline \multirow{2}{*}{ Patellar length } & \multirow{2}{*}{ Student's test } & \multirow{2}{*}{0.165} & Average & $39.2 \mathrm{~mm}$ & Average & $38.7 \mathrm{~mm}$ & \multirow{2}{*}{$\begin{array}{c}\text { Not statistically } \\
\text { significant }\end{array}$} \\
\hline & & & Range & {$[30.9-48.5] \mathrm{mm}$} & Range & {$[29.9-46.7] \mathrm{mm}$} & \\
\hline \multirow{2}{*}{$\begin{array}{l}\text { Inferior pole of } \\
\text { patella to joint } \\
\text { line distance }\end{array}$} & \multirow{2}{*}{ Student's test } & \multirow{2}{*}{0.419} & Average & $15.7 \mathrm{~mm}$ & Average & $15.9 \mathrm{~mm}$ & \multirow{2}{*}{$\begin{array}{c}\text { Not statistically } \\
\text { significant }\end{array}$} \\
\hline & & & Range & {$[2.1-29.9] \mathrm{mm}$} & Range & {$[4.7-58.9] \mathrm{mm}$} & \\
\hline \multirow{2}{*}{$\begin{array}{l}\text { Tibial tubercle } \\
\text { to joint line } \\
\text { distance }\end{array}$} & \multirow{2}{*}{ Student's test } & \multirow{2}{*}{0.229} & Average & $36.2 \mathrm{~mm}$ & Average & $36.7 \mathrm{~mm}$ & \multirow{2}{*}{$\begin{array}{c}\text { Not statistically } \\
\text { significant }\end{array}$} \\
\hline & & & Range & {$[24.9-46.7] \mathrm{mm}$} & Range & {$[28-47.4] \mathrm{mm}$} & \\
\hline \multirow{2}{*}{$\begin{array}{l}\text { Head of fibula } \\
\text { to joint line } \\
\text { distance }\end{array}$} & \multirow{2}{*}{ Student's test } & \multirow{2}{*}{0.010} & Average & $18.8 \mathrm{~mm}$ & Average & $17.5 \mathrm{~mm}$ & \multirow{2}{*}{$\begin{array}{l}\text { Statistically } \\
\text { significant }\end{array}$} \\
\hline & & & Range & {$[11.8-27.6] \mathrm{mm}$} & Range & {$[5.3-28.5] \mathrm{mm}$} & \\
\hline \multirow{2}{*}{$\begin{array}{l}\text { Medial } \\
\text { epicondyle } \\
\text { to joint line } \\
\text { distance }\end{array}$} & \multirow{2}{*}{ Student's test } & \multirow{2}{*}{0.136} & Average & $32.5 \mathrm{~mm}$ & Average & $33.1 \mathrm{~mm}$ & \multirow{2}{*}{$\begin{array}{c}\text { Not statistically } \\
\text { significant }\end{array}$} \\
\hline & & & Range & {$[23.5-42] \mathrm{mm}$} & Range & {$[26-41.8] \mathrm{mm}$} & \\
\hline
\end{tabular}




\begin{tabular}{|c|c|c|c|c|c|c|c|}
\hline \multirow{2}{*}{$\begin{array}{l}\text { Patellar length } \\
\text { / joint line to } \\
\text { tibial tubercle } \\
\text { ratio }\end{array}$} & \multirow{2}{*}{ Student's test } & \multirow{2}{*}{0.032} & Average & 1.1 & Average & 1.06 & \multirow{2}{*}{$\begin{array}{r}\text { Statistically } \\
\text { significant }\end{array}$} \\
\hline & & & Range & [0.88-1.33] & Range & [0.80-1.367] & \\
\hline $\begin{array}{c}\text { Parameter or } \\
\text { correlation }\end{array}$ & Type of test & Results & $\begin{array}{c}\text { Statistically } \\
\text { significant }\end{array}$ & $\begin{array}{c}\text { Parameter or } \\
\text { correlation }\end{array}$ & Type of test & Results & $\begin{array}{c}\text { Statistically } \\
\text { significant }\end{array}$ \\
\hline Sex - ROM & Student's test & 0.00009 & Yes & $\begin{array}{l}\text { BMI - Age at } \\
\text { surgery }\end{array}$ & Correlation test & -0.297 & Moderate \\
\hline Age - ROM & Correlation test & 0.0512 & No & $\begin{array}{c}\text { Gender - Age at } \\
\text { surgery }\end{array}$ & Student's test & 0.0048 & Yes \\
\hline BMI - ROM & Correlation test & $-0,279$ & Weak & $\begin{array}{c}\text { Type of TKA - } \\
\text { ROM }\end{array}$ & Student's test & 0.243 & No \\
\hline $\begin{array}{c}\text { Femoral } \\
\text { implant type - } \\
\text { ROM }\end{array}$ & Student's test & 0.0137 & Yes & $\begin{array}{l}\text { Patellar height } \\
\text { - ROM }\end{array}$ & Student's test & 0.261 & No \\
\hline $\begin{array}{c}\text { Femoral } \\
\text { component size } \\
\text { - ROM }\end{array}$ & Correlation test & 0.035 & No & & Correlation test & -0.052 & \\
\hline $\begin{array}{c}\text { Tibial implant } \\
\text { size - ROM }\end{array}$ & Correlation test & 0.0626 & No & $\begin{array}{l}\text { Insall-Salvati } \\
\text { ratio - ROM }\end{array}$ & Student's test & 0.149 & No \\
\hline $\begin{array}{c}\text { Spacer size - } \\
\text { ROM }\end{array}$ & Correlation test & -0.148 & No & & $\begin{array}{c}\text { Correlation test } \\
-0.109\end{array}$ & & \\
\hline
\end{tabular}

ROM: Range of Motion; BMI: Body Mass Index

\section{Discussion}

In order for a patient to regain an excellent flexion we consider that every aspect needs to be suitable, compared to a patient in which the range of motion is below 130 degrees, where many issues may occur. Our study suggests that against prior believes, joint line to fibula head distance can be significantly higher than the reference value of $15 \mathrm{~mm}$ and still be associated with excellent range of motion, with an interval of 12 to $27 \mathrm{~mm}$ [6]. Moreover, the average in the excellent range of motion group was higher that the good range of motion group (18.8 $\mathrm{mm}$ vs. $17.7 \mathrm{~mm}$ ). Another aspect our study pointed out was that patella length / joint line to tibial tubercle ratio interval should range between 0.9 and 1.3 for an excellent clinical outcome. Anything under or above this range is associated with a lowering in maximum ability to flex the operated knee. We have found no studies regarding this issue in the current literature.

Narrow femoral implants from Zimmer Persona were associated with a better flexion compared to standard ones, but a limitation of our study regarding this concern is the low number of narrow femoral implants $(n=23)$. Therefore we consider that this aspect should be further studied on larger groups. No significant difference has been found between excellent ROM and good ROM groups in age (range 48 to 85 years old). The same result was obtained for body mass index, accordingly to other studies [7]. We find these data important for the prognostic of clinical outcome and reassuring patients. A fact proven by our study and in favor of bilateral total knee replacements (BTKA) is that there was no significant difference in ROM compared to the unilateral total knee replacements [8-
10]. Moreover, the average in flexion degrees was higher in BTKA compared to unilateral TKA (129 degrees vs. 127 degrees). We admit that the low number of unilateral TKA $(n=24)$ in our study show the need of a larger study to test our results on this matter, although other studies performed by Maniar, Zeni and Powell had the same result, but with the same limitation [8-10].

Other measurements and ratios such as patella length, inferior pole of patella to joint line distance, tibial tubercle to joint line distance, medial epicondyle to joint line distance and Insaal-Salvati ratio were not significantly correlated with ROM. We consider important sharing the ranges associated in our database with excellent range of motion for all measurements for surgeons to know how much they can modify these distances without affecting the range of motion. The study also demonstrated that men have a better flexion after TKA compared to female (average difference of 6 degrees) is according to Ritter and Campbell's findings [11]. Our study's result that men need TKA later that female (average difference of 5 years) is contrary to. Parsley's findings which have the advantage of a higher number of cases, but we consider that the difference between Arab culture in our study and American culture in Parsley's study can play an important role in the mismatch [12].

The limitations of the study include small number of patients in some cases, which were stated before. Moreover we could not include all the patients within the period of time, but only those which did physiotherapy at our institution. Another limitation is that when performing lateral $\mathrm{x}$-ray measurements, most knees were not precisely at a 90 degree flexion, a fact that could affect our measurements. For this issue we have done testing and 
we concluded that within a range of $90 \pm 20$ degrees of flexion, measurements are only slightly changed and do not affect final results.

Our study also has strengths including high number of patients, the same team following the same protocol in the same institution and the same physiotherapy department. The measurements were done by the same person in all cases and checked twice. Moreover all of the patients included in the study were Arabic. By our knowledge it is the first study to do so many measurements on such a high number of patients. Some of the measurements have never been assessed before. Also, by our knowledge, it is the first study to provide ranges of these measurements which allow an excellent range of motion.

\section{Clinical Importance}

A major goal of primary and revision total knee arthroplasty is to restore normal knee kinematics. This can be accomplished by balancing soft tissues and the remaining bony anatomy of the knee. Joint line malposition can lead to various problems. Elevating the joint line $(>8 \mathrm{~mm})$ results in motion problems and can lead to mid-flexion instability and patellofemoral tracking problems. Similarly, lowering joint line can lead to lack of full extension and flexion instability. Every attempt should be undertaken to place the joint line in the correct anatomical position.

\section{Conclusion}

Our study suggests that joint line to fibula head distance can be significantly higher than the reference value of $15 \mathrm{~mm}$ and still be associated with excellent range of motion; the average in the excellent range of motion group was $18.8 \mathrm{~mm}$. Another aspect was that patella length / joint line to tibial tubercle ratio interval should range between 0.9 and 1.3 for an excellent clinical outcome. Anything out of this range is associated with less ability to flex the knee. Re-establishing a correct joint line position is recognized as one of the most important factors in achieving normal ligament balance and normal knee kinematics.

\section{References}

1. Martin GM (2017) Patient education: Total knee replacement (arthroplasty) (Beyond the Basics). In: Up To Date, Post TW (Ed), Walthanm MA, USA.

2. Lúcio Honório de Carvalho Júnior, Luiz Fernando Machado Soares, Matheus Braga Jacques Gonçalves, Marcelo Lobo Pereira, Rodrigo Rosa Lessa, et al. (2011) Relationship between patellar height and range of motion after total knee arthroplasty. Rev Bras Ortop 46(4): 408-411.

3. Meneghini RM, Ritter MA, Pierson JL, Meding JB, Berend ME, et al. (2006) The effect of the Insall-Salvati ration in outcome after total knee arthroplasty. J Arthroplasty 31(6): 116-120.

4. Pereira GC, von Kaeppler E, Alaia MJ, Montini K, Lopez MJ, et al. (2016) Calculating the Position of the Joint Line of the Knee Using Anatomical Landmarks. Orthopedics 39(6): 381-386.

5. Dai Y, Scuderi GR, Penninger C, Bischoff JE, Rosenberg A (2014) Increased shape and size offerings of femoral components improve fir during total knee arthroplasty. Knee Surg Sports Traumatol Arthrosc. 22(12): 2931-2940.

6. Havet E, Gabrion A, Leiber-Wackenheim F, Vernois J, Olory B, et al (2007) Radiological study of the knee joint line position measured from the fibular head and proximal tibial landmarks. Surg Radiol Anat 29(4): 285-289.

7. Anouchi YS, McShane M, Kelly F Jr, Elting J, Stiehl J (1996) Range of motion in total knee replacement. Clin Orthop Relat Res (331): 87-92.

8. Maniar RN, Baviskar JV, Singhi T, Maniar P, Nayak R (2013) Influence of bilateral sequential total knee arthroplasty on functional recovery. Indian J Orthop 47(1): 23-30.

9. Zeni JA Jr., Snyder-Mackler L (2010) Clinical Outcomes After Simultaneous Bilateral Total Knee Arthroplasty: Comparison to Unilateral Total Knee Arthroplasty and Healthy Controls. J Arthroplasty 25(4): 541-546.

10. Powell RS, Pulido P, Tuason MS, Colwell CW, Ezzet KA (2006) Bilateral vs Unilateral Total Knee Arthroplasty: A Patient-Based Comparison of Pain Levels and Recovery of Ambulatory Skills. J Arthroplasty 21(5): 642-649.

11. Ritter MA, Campbell ED (1987) Effect of range of motion on the success of a total knee arthroplasty. The Journal of Arthroplasty 2(2): 95- 97.

12. Parsley BS, Bertolusso R, Harrington M, Brekke A, Noble PC (2010) Influence of Gender on Age of Treatment with TKA and Functional Outcome. Clin Orthop Relat Res 468(7): 1759-1764.

\section{Your next submission with Juniper Publishers} will reach you the below assets

- Quality Editorial service

- Swift Peer Review

- Reprints availability

- E-prints Service

- Manuscript Podcast for convenient understanding

- Global attainment for your research

- Manuscript accessibility in different formats

( Pdf, E-pub, Full Text, Audio)

- Unceasing customer service

Track the below URL for one-step submission https://juniperpublishers.com/online-submission.php 